\title{
EVALUATING NOISE IN DIGITIZED RADIOGRAPHIC IMAGES BY MEANS OF HISTOGRAM
}

\author{
AVALIAÇÃO DE RUÍDO EM IMAGENS RADIOGRÁFICAS DIGITALIZADAS \\ POR MEIO DO HISTOGRAMA
}

Izabel Regina Fischer RUBIRA-BULLEN ${ }^{1}$, Maurício Cunha ESCARPINATI ${ }^{2}$, Homero SCHIABEL ${ }^{3}$, Marcelo Andrade da Costa VIEIRA ${ }^{2}$, Cássia Maria Fischer RUBIRA ${ }^{4}$, José Roberto Pereira LAURIS ${ }^{5}$

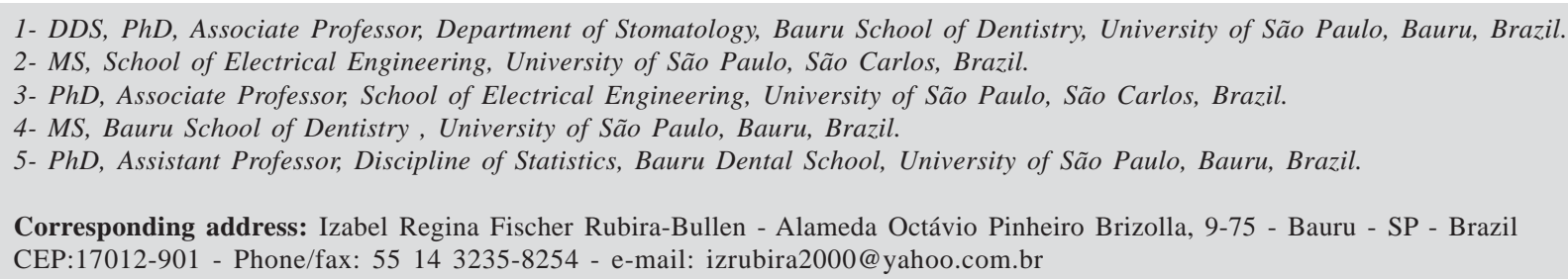

\begin{abstract}

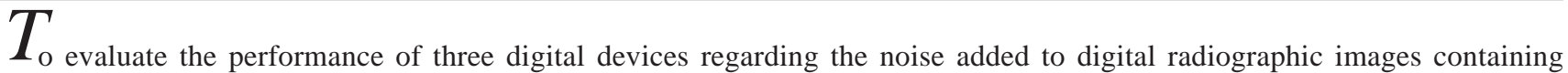
different optical densities. Methods: A radiographic image was digitized repeatedly ten times using two scanners (HP 4c/T and HP 5370C) and a digital camera (Nikon 990). A histogram tool measured a mean pixel value and the standard deviation of the region of interest in each image. Both values were used to calculate the image noise at the different optical densities. Results: The noise values found were different for all devices and optical densities. There was a statistically significant difference $(\mathrm{p}<0.05)$ between the scanner HP 4c/T and the digital camera regarding the noise values. There was a significant correlation $(\mathrm{p}<0.05)$ between the noise values found for the HP 4c/T scanner and the digital camera and between both scanners $(\mathrm{p}<0.01)$. Conclusions: The noise added to the image was higher for scanner HP 4c/T and less for the digital camera. The noise was higher at the lower optical densities for the scanners. It seems that depending on the equipment and the optical density, a variable amount of noise can be incorporated to the images.

Uniterms: Digital image; Radiographic image; Scanners; Digital camera; Charge-coupled device; Noise.
\end{abstract}

\begin{abstract}
RESUMO
$O$ bjetivos: Avaliar três equipamentos digitais em relação ao ruído agregado as imagens radiográficas digitalizadas contendo diferentes densidades ópticas. Material e Métodos: Uma imagem radiográfica foi digitalizada seqüencialmente dez vezes usando dois escaneres (HP 4c/T and HP 5370C) e uma câmera digital (Nikon 990). Por meio do histograma foram medidos os valores de pixels e os desvios-padrões da região de interesse de cada imagem. Ambos valores foram utilizados para o cálculo do ruído nas diferentes densidades ópticas. Resultados: Os valores encontrados para o ruído foram diferentes para cada equipamento e para cada densidade óptica. Houve uma diferença estatística significante entre os valores de ruído encontrados para o escaner HP 4c/T e a câmera digital $(\mathrm{p}<0.05)$. Houve uma correlação significante entre os valores do ruído encontrados para o escaner HP 4c/T e a câmera digital $(\mathrm{p}<0.05)$ e entre os dois escaneres $(\mathrm{p}<0.01)$. Conclusões: O ruído agregado à imagem foi maior para o escaner HP 4c/T e menor para a câmera digital. O ruído foi maior nas densidades ópticas menores para os dois escaneres. Dependendo do equipamento e da densidade óptica uma quantidade variável de ruído pode ser agregado às imagens.

Unitermos: Imagem digital; Imagem radiográfica; Escaner; Câmera digital; Dispositivo de carga acoplada; Ruído.
\end{abstract}




\section{INTRODUCTION}

Digital devices such as film digitizers or digital cameras are commonly found in Radiology departments and are used to create digital image files from conventional (analog) radiographic films ${ }^{5,12}$. Emerging technologies such as picture archive and communication systems have become more widespread so that film digitizers will continue to find applications until direct digital x-ray capture technology completely replaces film-based radiology $y^{7,8,9}$. Basically, a digitizer converts optical density (OD) information in the radiographic image into pixel values, which are interpreted by the computer to build the digital image. Flatbed scanners with a transparency adapter and digital cameras operate by transillumination of the radiograph from a light source in order to obtain a digital image. Because the digitization process varies from equipment to equipment, it is necessary to know at which optical densities the noise might be interfering with the image.

The present study was based on the hypothesis that using a calculation based on mean and standard deviation pixel values, it is possible to evaluate the noise of digital equipment used for radiographic image capture. Therefore, three digital devices were tested regarding the noise added to the image.

\section{MATERIALAND METHODS}

A ten-step exposure on an occlusal film (Insight, Kodak, Rochester) was obtained with a sensitometer (Dual-Flashing, Nuclear Associates, USA). The use of a sensitometer offered a very small OD difference between each consecutive step. The film was processed by standardized temperature-time method. The optical densities (OD) were measured (Little Genius, Nuclear Associates) for each step. Using the same capture parameters, the image (occlusal film) was digitized ten times by two scanners (HP 4c/T and HP 5370C, HewlettPackard Co., USA) and a Nikon Coolpix 990 (Japan) digital camera. The capture parameters were 600 dpi for the two scanners and saved in TIF format. The digital camera was set to a maximum resolution of $2048 \times 1360$ pixels in TIF format (300 dpi). The digital gray scale was set so that zero represented white and 255 black, to correlate directly to the optical densities. The OD obtained from the radiographic image were: step 1 and $2=0.25$, steps 3 and $4=0.26$, step 5 $=0.28$, step $6=0.32$, step $7=0.41$, step $8=0.65$, step $9=1.15$, and step $10=2.02$.

\section{Calculation of the noise $(\mathrm{N})$}

After digitization, the standard deviations (SD) and pixel values were obtained using the ImageJ software (NIH, USA). The histogram tool measured an area of 17,000 pixels for each step in every image. The pixel values from the 10 images obtained for each device were transformed in a mean and the same it was performed for the standard deviation values. The standard deviation and the pixel values were used in a formula.

The formula applied was: SD/pixel value*100. The results were considered as the noise $(\mathrm{N})$ values $^{17,18,22}$.

\section{RESULTS}

Table 1 shows the mean pixel values $(\mathrm{M})$ and the mean standard deviation (MSD) obtained from the ten images, which were used in the formula to calculate the noise $(\mathrm{N})$.

Table 2 shows the OD related to the noise (N) for each step and equipment.

The correlation indices (Spearman) were: 0.8 between the two scanners $(\mathrm{p}<0.01), 0.6$ for the digital camera and scanner HP 4c/T $(\mathrm{p}<0.05)$, and 0.6 for the digital camera and scanner HP 5370C ( $p>0.05)$. The Friedman analysis showed a statistically significant difference among the three devices $(p<0.05)$. The Dunn's multiple comparison test pointed a statistically significant difference between the scanner Hp $4 \mathrm{c} / \mathrm{T}$ and the digital camera $(\mathrm{p}<0.05)$.

TABLE 1- Pixel value and Standard deviation, respectively, Pv1/SD1 obtained for the HP 4c/T scanner, Pv2/SD2 for HP 5370, and PV3/SD3 for digital camera

\begin{tabular}{|c|c|c|c|c|c|c|}
\hline Step & Pv1 & SD1 & Pv2 & SD2 & Pv3 & SD3 \\
\hline 1 & 4.8 & 3.7 & 33.8 & 3.5 & 52.0 & 1.8 \\
\hline 2 & 6.1 & 4.03 & 3.7 & 3.5 & 50.0 & 1.9 \\
\hline 3 & 9.2 & 4.53 & 4.9 & 3.7 & 49.7 & 1.7 \\
\hline 4 & 13.5 & 4.83 & 6.8 & 3.9 & 49.7 & 1.8 \\
\hline 5 & 23.7 & 4.64 & 0.8 & 4.2 & 52.7 & 1.7 \\
\hline 6 & 44.4 & 5.15 & 0.5 & 4.7 & 59.7 & 1.8 \\
\hline 7 & 83.3 & 5.37 & 0.7 & 5.3 & 75.3 & 2.2 \\
\hline 8 & 155.8 & 5.41 & 15.4 & 6.0 & 112.2 & 2.6 \\
\hline 9 & 222.3 & 3.91 & 78.5 & 6.3 & 178.9 & 4.7 \\
\hline 10 & 248.5 & 1.72 & 43.2 & 8.0 & 238.3 & 2.6 \\
\hline
\end{tabular}




\section{DISCUSSION}

It seems clear that each device has its own way to attribute pixel values once there was variability among them regarding this aspect (Table 1 ). We may consider these differences understandable once each device has its own built-in parts different from each other.

The digital camera presented a lower digitization noise (N) than the two scanners (Table 2), showing low mean standard deviation values (Table 1). It seems that the noise incorporated into the image was low for each digitization. Probably, the CCD of the digital camera was manufactured in such a way as to equilibrate the image noise and the signal, with a higher signal-to-noise ratio (SNR) $)^{1,3,4,19,20}$. The CCD of scanners may differ in terms of the SNR. Probably, the CCDs of the scanners had less efficient mechanisms for noise removal. Table 2 clearly showed a large amount of noise for the two scanners in relation to the digital camera, being worse for scanner $\mathrm{HP} 4 \mathrm{c} / \mathrm{T}$.

Analyzing Table 2, it seems that the two scanners showed less noise values at the denser steps 9 and 10, OD 1.15 and 2.02 respectively.

The largest difference between the three devices was observed in terms of the illumination source, which unfortunately cannot be the same since each of the two scanners has its own light source and a film viewer was used for the digital camera. This fact could explain the reason why the devices attributed different pixel values and standard deviations to each step.

The trajectory of light differed between the scanner and digital camera. Whereas in the case of the scanners the light first passes the film and then the glass before reaching the CCD, in the digital camera the light first passes the acrylic of the film viewer, then the film and finally reaches the CCD. It is difficult to confirm that this difference in sequence influenced the results but the possibility exists, considering that light undergoes modifications when passing from one

TABLE 2- Results of N obtained for the HP 4C/T, HP 5370C scanners and digital camera in relation to steps and OD (optical density)

\begin{tabular}{lllll}
\hline Steps & OD & \multicolumn{1}{c}{$\mathbf{N}$} & \multicolumn{1}{c}{$\mathbf{N}$} & $\mathbf{N}$ \\
& & HP4c/T & HP 5370C & DC \\
\hline 1 & 0.25 & 77.0 & 10.3 & 3.4 \\
2 & 0.25 & 65.5 & 10.3 & 3.8 \\
3 & 0.26 & 48.9 & 10.6 & 3.4 \\
4 & 0.26 & 35.5 & 11.1 & 3.6 \\
5 & 0.28 & 19.4 & 10.3 & 3.2 \\
6 & 0.32 & 11.4 & 9.3 & 3.0 \\
7 & 0.41 & 6.3 & 7.5 & 2.9 \\
8 & 0.65 & 3.4 & 5.2 & 2.3 \\
9 & 1.15 & 1.7 & 3.5 & 2.6 \\
10 & 2.02 & 0.7 & 3.3 & 3.4 \\
\hline
\end{tabular}

medium to another. Digital cameras eliminate noise resulting from dark current or masking pixels (Nikon 990) or taking a second photograph in the dark to subtract from the original image, and thus eliminate the influence of this noise on the final pixel value $e^{1,3,4,19,20}$. Probably due to this mechanism a smaller $\mathrm{N}$ was obtained for the digital camera compared to the scanners.

Moreover, noise related to post-capture mechanisms, such as the A/D converter or exit amplifier could modify the pixel value. If both mechanisms were unable to keep the signal adequately from the first to the last digitization, it may have contributed for the larger noise amount related to the scanners. Still considering this situation, the interaction between light and the silicon of the CCD and formation of the depletion zone may be compromised when sequential digitizations are done. If the depletion zone is not formed with the adequate depth, a lower amount of charge will be collected from the first to the tenth digitization ${ }^{6,11,14}$. Therefore, this fact could have increased the standard deviation values for the two scanners. Thus, increasing the standard deviation increases the noise.

The noise incorporated into the image increased compared to the digital camera for both scanners, being higher for scanner HP 4c/T. This greater noise might also be the result of an increase of the dark current, because of heating of the CCD due to consecutive exposures, and this noise was not efficiently eliminated, leading to a higher standard deviation of each pixel or incorporation of a greater noise during post-sensor processing.

The results obtained for HP 5370 and the digital camera revealed similar pixel values for the two devices from step 1 to step 6, during which the ODs suffered little variation ( 0.25 to 0.32 ). On the other hand, HP 4c/T attributed very different values even for the same ODs (Table 1), such as observed for steps 1 and 2, 3 and 4 . This difference might be noise incorporated during motor carriage moving since the steps were placed at different positions on the film, or the light incidence was different as the scanner ran the film.

Comparison of the two scanners showed higher pixel values for scanner HP 4c/T, i.e., the capturing of light and its transformation into an A/D signal was much more variable for its CCD (Table 1). The pixel values captured by HP 5370 were quite uniform but, on the other hand, this device incorporated greater noise than the digital camera.

Still with respect to the noise $(\mathrm{N})$, the largest differences were observed for steps 1 to 8 , i.e., the least dense steps (lower OD). It seems that the less dense steps had a tendency to show more noise. Table 2 clearly shows the decrease in $\mathrm{N}$ from step 1 to step 10 for the two scanners. The saturation phenomenon (blooming) of the CCD might influence these results. Not all CCDs possess drain mechanisms to prevent saturation ${ }^{6,11,14}$.

Wide variations in noise from step 1 to step 8 were observed for the scanner HP 4c/T, while more constant and similar values were obtained for the HP 5370 and the digital camera, again suggesting that the HP 4c/T had a more erratic behavior than the other two devices.

Nevertheless, the denser steps 9 and 10 showed a lower 
noise amount for both scanners, either because they captured the values of these areas with relative quality or they were areas less penetrated by light, which led to uniformity in the capture and thus resulted in a lower standard deviation. Another hypothesis would be that in these denser areas the saturation phenomenon did not occur and the quality of image capture was thus increased.

The steps 9 and 10 possess a clinically useful OD of about 1 and $2^{17,22}$ so that the three devices were able to discriminate these two densities. A decrease in noise was noted at the border between step 6 and step 7 for all devices (Table 2).

In the denser steps 8, 9 and 10, scanner HP 4c/T attributed higher pixel values, in contrast to the other two devices, although this same scanner attributed lower values in steps 1 to 6 than the other two devices (Tables 1 ). This inconsistency in performance might be related to the incoherent mode of how its CCD receives light from more or less dark areas ${ }^{10}$. When the area tended to be clearer, higher noise was obtained.

The higher noise amount of scanner HP 4c/T compared to HP 5370 and the completely different behavior of the digital camera, which showed much lower noise than the other two devices, were clearly demonstrable (Table 2).

The mean standard deviations obtained for steps 8, 9 and 10 (denser steps) showed a marked decrease compared to the other steps for scanner HP 4c/T and the digital camera but increased for the HP 5370. In these steps, the HP 5370 obtained a higher noise amount exactly because of the increase in its standard deviation. In the denser steps, the HP 5370 showed a worse performance than scanner Hp 4c/ $\mathrm{T}$, adding greater noise amount to the image. The digital camera occupied an intermediate position between the two scanners in terms of standard deviation values.

With respect to noise, for the clear steps the best performance was observed for the digital camera followed by HP 5370. For the dark steps, the HP 4c/T and the digital camera showed the best performance. Thus, none of the devices provided the best characteristics along all density steps regarding noise.

The importance of information about the performance of digitization equipment lies exactly in knowing in which regions of the image the device can obtain the best characteristics for the final image $e^{2,13,23}$. Digitizers such as scanners or digital devices will continue to be part of a transition period which will ultimately lead to the direct digital image, and therefore their quality continues to be important ${ }^{10,15}$. The calculations showed could be applied to evaluate any digital equipment (direct or indirect) in order to determine the noise related to the image. Hangieandreou, et $\mathrm{al}^{16}$ concluded from their findings that CCD digitizers were not able to produce a reliable digital translation of plain radiographs because of their limitations in density range. Furthermore, Schulze, et al. ${ }^{21}$ detected a significant loss of information particularly in dark zones of high OD of digitized panoramic radiographs. In our study the darker zones showed less noise associated to the images.

These conclusions and our findings regarding the noise on the image in consecutive digitizations may influence clinical results mainly based on pixel values, i.e. healing process evaluation. It is maybe advisable to test digital devices, whether direct or indirect, regarding the noise prior quantitative image analysis. A considerable advance in the use of these devices would be the implementation of a digitization protocol that would include the minimum quality requirements that the final image should exhibit.

\section{REFERENCES}

1- Anatomy of digital camera [text on the internet]. Extremetech. [cited 2006 Aug 28]. Available from: http://www.extremetech.com/ article2/0,1697,1152062,00.asp.

2- Attaelmanan A, Borg E, Gröndhal HG. Digitisation and display of intra-oral films. Dentomaxillofac Radiol. 2001;29:97-102.

3- Autiokari T. Subtracting the Dark current noise [text on the internet]. Accurate Image Manipulation. [cited 2006 Aug 28]. Available from:

http://www.aim-dtp.net/aim/techniques/dark_current_noise/ index.htm.

4- Bebek C, Groom D, Holland S, Karcher A, Kolbe W, Lee J, et al. Proton radiation damage in p-channel CCDs fabricated on highresistivity silicon [text on the internet]. SNAP. [cited 2006 Aug 28]. Available from:

h t t p : / / s n a p. l b l . g o v / p u b d o c s / CCDpaper_rev2.pdf\#search=\%22ccd\%20depletion\%20zone\%22.

5- Berkhout WER, Sanderinck GCH, Van der Stelt PF. A comparasion of digital and film radiography in Dutch dental practices assessed by questionnaire. Dentomaxillofac Radiol. 2002;31:93-9.

6- Charge collection in a ccd [text on the internet]. Isaac Newton Group of Telescopes. [cited 2006 Aug 28]. Available from:

h t t p : / / w w w. i n g. i a c. e s / s m t / re d s e n s e / deep_depletion.PDF\#search=\%22ccd\%20depletion\%20zone\%22.

7- Chen SK. Integration of the digital imaging and communications in medicine standart into an oral and maxillofacial image management and communication system. Oral Pathol Oral Med Oral Radiol Endod. 2001;91(2):235-8.

8- Chen SK, Hollender L. Digitizing of radiographs with flatbed scanner. J Dent. 1995;23:205-8.

9- Christian ME, Davidson HC, Wiggins RH, Berges G, Cannon G, Jackson G, et al. Digital Processing of radiographic images from PACS to publishing. J Digit Imaging. 2001;14 (1):14-7.

10- Clark K, Dawson WB, Muka E, Pilgram TK, Blaine J. Study involving laser digitized versus CCD-digitized images. J Digit Imaging. 2002;15 Suppl 1:53-6.

11- Concepts in digital imaging technology [text on the internet]. Microscopy Resource Center. [cited 2006 Aug 28]. Available from: http://www.olympusmicro.com/primer/digitalimaging/concepts/ concepts.html.

12- Dzingle D, May GA, Garaland HT. Digital radiography and film scanners: automating the transition to filmless radiology. J Digit Imaging. 2001;14(2):128-30.

13- Escarpinati, MC, Vieira, MA, Schiabel, H. Computer technique for digital radiographic images correction on the digitizer characteristic curve. J Dig Imaging. 2002;15:228-30. 
14- Fellers TJ, Vogt KM, Davidson MW. CCD Signal-To-Noise Ratio [text on the internet]. Nikon MicroscopyU. [cited 2006 Aug 28]. Available from: http://www.microscopyu.com/tutorials/java/ digitalimaging/signaltonoise/index.html.

15- Hall FM, Esterbrook L. Megapixel digital câmera. AJR Am J Roentgenol. 2000;174:1462-3.

16- Hangiandreou NJ, O`Connor TJ, Felmlee JP. An evaluation of the signal and noise characteristics of four CCD-Based film digitizers. Med Phys. 1998;25(10):2020-6.

17- Hildebolt CF, Vannier MW, Pilgram TK, Shrout MK. Quantitative evaluation of digital dental radiograph imaging systems. Oral Surg Oral Med Oral Pathol. 1990;70:661-8.

18- Hildebolt CF, Fletcher G, Yokoyama-Crothers N, Conover GL, Vannier MW. A comparasion of the response of storage phosphor and film radiography to small variations in $x$-ray exposure. Dentomaxillofac Radiol.1997;26:147-51.

19- How digital cameras work [text on the internet]. Bythom. [cited 2006 Aug 28]. Available from: http://www.bythom.com/ccds.htm.

20- Hytti HT. Characterization of digital image noise properties based on RAW data [text on the internet]. Measurement and Information Technology. [cited 2006 Aug 28]. Available from: http:/ / w w w. m i t. t u t. f i / s t a f f / H y t i / Noise characterization.pdf\#search=\%22dark\%20current\%20digital\%20camera\%22

21- Schulze RK, Rosing ST, D’Hoedt B. Contrast perception in digitized panoramic radiographs compared with their film-based origin. Oral Surg Oral Med Oral Pathol Oral Radiol Endod. 2002;94(3):388-94.

22- Shrout MK, Potter BJ, Yugalavage HM, Hildebolt CF, Vannier MW. 35-mm film scanner as an intraoral dental radiograph digitizer. I: a quantitative evaluation. Oral Surg Oral Med Oral Pathol. 1993;76(4):502-9.

23- Teslow TN. The laser film digitizer: density, contrast, and resolution. J Digit Imaging. 1997;10:128-32. 